\title{
Stakeholder Participation in the Planning and Design of Nature-Based Solutions. Insights from CLEVER Cities Project in Hamburg
}

\author{
Alessandro Arlati ${ }^{1, * \mathbb{C}}$, Anne Rödl ${ }^{2} \mathbb{D}$, Sopho Kanjaria-Christian ${ }^{3}$ and Jörg Knieling ${ }^{1}$ \\ 1 Department of Urban Planning and Regional Development, HafenCity University Hamburg, \\ Henning-Voscherau-Platz 1, 20457 Hamburg, Germany; joerg.knieling@hcu-hamburg.de \\ 2 Institute of Environmental Technology and Energy Economics, Hamburg University of Technology, \\ Eissendorfer Straße 40, 21073 Hamburg, Germany; anne.roedl@tuhh.de \\ 3 Free and Hanseatic City of Hamburg, District of Harburg, Harburger Rathausplatz 4, 21073 Hamburg, Germany; \\ sophio.konjaria-christian@harburg.hamburg.de \\ * Correspondence: Alessandro.arlati@hcu-hamburg.de
}

Citation: Arlati, A.; Rödl, A.; Kanjaria-Christian, S.; Knieling, J. Stakeholder Participation in the Planning and Design of Nature-Based Solutions. Insights from CLEVER Cities Project in Hamburg. Sustainability 2021, 13, 2572. https:// doi.org/10.3390/su13052572

Academic Editor: Israa H. Mahmoud

Received: 4 December 2020

Accepted: 23 February 2021

Published: 27 February 2021

Publisher's Note: MDPI stays neutral with regard to jurisdictional claims in published maps and institutional affiliations.

Copyright: (c) 2021 by the authors. Licensee MDPI, Basel, Switzerland. This article is an open access article distributed under the terms and conditions of the Creative Commons Attribution (CC BY) license (https:// creativecommons.org/licenses/by/ $4.0 /)$.

\begin{abstract}
Cities are essential players in responding to the present complex environmental and social challenges, such as climate change. The nature-based solution ( $\mathrm{NbS}$ ) concept is identified in the scientific discourse and further recognized by the European Commission as a part of the solution to address such challenges. Deploying $\mathrm{NbS}$ in urban contexts requires the cooperation of different public and private stakeholders to manage those processes. In this paper, the experiences of establishing and managing NbS-related processes following a co-creation approach in the city of Hamburg within the framework of an EU-funded research project (CLEVER Cities) are described and analyzed. The paper identifies and discusses the main emerging factors and challenges from (1) a procedural and methodological perspective and (2) concerning the different roles of the diverse stakeholders involved. This discussion is grounded in the context of existing regulations and novel concepts for citizens' participation in urban decision-making processes. As research results, the article defines the leading players involved in the process and their roles and interrelationships, along with recommendations for future policy agendas in cities when dealing with NbS planning.
\end{abstract}

Keywords: stakeholder participation; nature-based solutions; multi-level governance; co-creation; urban living lab; sustainable urban development; urban planning

\section{Introduction}

Climate change poses cities complex environmental and social challenges. After an era of mainly favoring economic growth to the detriment of natural capital, the dual objective of addressing both elements entered European cities' political agendas [1] (p. 121). The inherent complexity of dealing with environmental and social demands requires a paradigm shift in policy-making [2].

In the 2010s, the concept of nature-based solutions ( $\mathrm{NbS}$ ) emerged in the political agendas of cities that are committed to becoming more "resilient, invest into green infrastructure and integrate nature-based solutions to improve microclimate, limit urban heat island phenomenon and improve air quality" [3] (p. 93). Given the fact that NbS are "designed to address various societal challenges in a resource-efficient and adaptable manner and to provide simultaneously economic, social and environmental benefits" [1] (p. 121), it appears that the simultaneity of addressing challenges related to the three pillars of sustainability is one of the main objectives that can be reached through $\mathrm{NbS}$. Furthermore, Frantzeskaki et al. [4] argue that $\mathrm{NbS}$ can be potent tools to mitigate the effects of extreme weather events and provide additional adaptation strategies for urban settlements. The European Commission has also largely adopted the NbS concept [5], such as in the Horizon 2020 Funding Programme [6]. IUCN [7] has recently published criteria for 
verification, design, and scaling up of $\mathrm{NbS}$ to support national governments, local governments, planners, businesses, or organizations. Among the IUCN-defined criteria, the fifth states that, $\mathrm{NbS}$ should be based on inclusive, transparent, and empowering governance processes [7] (p. 14). This implies using the existing regulatory framework concerning participatory processes and eventually stimulating the finding of novel tools towards conducting a transparent and open process of co-creation. In this context, co-creation means allowing stakeholders to collaborate in the process of solution design, implementation, and monitoring [3,8]. In this sense, the co-creation of $\mathrm{NbS}$ is understood as a combination of various expertise from different scientific fields and the local knowledge of civil society representatives [9].

Kemp and Loorbach [10] argue that working towards sustainable development requires simultaneous communication between different governance levels. As also Frantzeskaki et al. [11] (p. 23) state, it is necessary to involve a wide range of stakeholders in decision-making processes at every level to create collective action for a more sustainable approach to shaping cities. Hence, decision-making processes within the field of sustainable development occur by participative momenta of exchange among composite governmental and non-governmental stakeholder constellations. This is reflected in the need to establish an everyday discourse based on the broad participation that includes both practitioners and laypersons. In this context, cities' governance structures may contain elements that can hinder or encourage participation depending on their hierarchies/political structures and processes, and they might require modifications.

This article was developed in the framework of the European-funded H2020 project CLEVER Cities, which deploys $\mathrm{NbS}$ to address urban challenges and social inclusion in cities [12]. CLEVER Cities' activities focus on the impacts of NbS on social cohesion, citizen security, environmental justice, and human health. Accordingly, the development of $\mathrm{NbS}$ happens through the active participation of local stakeholders following a co-creation logic called the Co-Creation Pathway [3]. This pathway is described in more detail in Section 2. The idea behind the Co-Creation Pathway is the broader concept of Urban Living Labs (ULL), which are conceived here as forums of innovation where resources and agencies are moving towards governed sustainable development [13] with the long-term objective of achieving resilient and climate-responsive cities [3].

By discussing how the co-creation process of NbS-including planning, design, and implementation phases-happened for the case study of Hamburg, the paper aims to answer the following question: which stakeholders should be involved in the co-creative process of the planning and design of $\mathrm{NbS}$ and which roles do they play in the different phases? The article explores which types of stakeholders contributed to the definition of the $\mathrm{NbS}$ and discusses their roles in the three Urban Living Labs (ULL) that were part of the CLEVER Cities project. Insights are provided into the tools and methods that supported the co-creation process's goals and facilitated stakeholders' inclusion. As an outcome, the article defines recommendations for future policy agendas in cities when dealing with $\mathrm{NbS}$.

\section{Materials and Methods}

This section illustrates the methodology delineated for answering the research question and a brief introduction to the CLEVER Cities project area.

\subsection{Methodology}

The Co-Creation Pathway elaborated within the CLEVER Cities project by Morello et al. [14] describes a five-phase concept of co-creation to be applied in the development of NbS-namely, (i) urban innovation partnership (UIP) establishment, (ii) codesign, (iii) co-implementation, (iv) co-monitoring, and (v) co-development. Within the local project area, stakeholders are engaged to form partnerships (i) to go through the entire process from (ii) to (v). The first phase considers the establishment of a UIP. Morello et al. [14] (p. 90) describe the UIP as a "city-wide or district-focused informal alliance" between various local authorities and community groups, businesses, and academics to 
promote $\mathrm{NbS}$ to foster urban regeneration. Ideally, this alliance formation follows the quadruple helix concept [15], which denotes the neo-institutional networks between the government, business sector, academia, and civil society that have the task of steering and facilitating the co-creation process in the project area.

During the co-design phase (ii), the UIP members organize workshops to jointly design nature-based interventions that help to solve local, social, environmental, and economic challenges. To guide the co-design process effectively, the methodological approach Theory of Change (ToC) [16] represents the primary reference for the definition of the $\mathrm{NbS}$. The method consists of a systematic process that brings the attendees to address local challenges through the conception of a long-term vision. It is then necessary to work backward by setting out the overall, intermediate, and short-term outcomes and outputs to achieve the defined vision [17] (p. 12; adapted from [16]).

The second phase's solutions are operationalized in the third phase (co-implementation phase) by involving and working closely with citizens and other relevant stakeholders. The fourth phase of the pathway comprises the co-monitoring process, in which the interventions' impact, durability, and quality are evaluated. The involvement of citizens is expected in all four phases.

The final phase, co-development, describes the UIP members' and citizens' joint efforts to maintain the interventions and eventually replicate them in other parts of the city (upscaling). The presented Co-Creation Pathway results in introducing shared governance arrangements [18] that facilitate and guide the transition process with multi-level $[19,20]$ and multi-stakeholders approaches [21].

At the time this paper was written (November 2020), the CLEVER Cities project is between phase two (ii), co-design, and phase three (iii), co-implementation. Hence, only the first two phases (namely, UIP establishment and co-design) are discussed here, including the descriptions of tools, methods, and procedures. Additionally, stakeholders' participation in NbS planning, design, and implementation is analyzed for the Hamburg case study's practical example. Therefore, a stakeholder analysis was conducted to depict the stakeholders' constellation and their characteristics in the NbS planning process-namely, providing resources and goals and taking on decision-making power and roles. The analysis was performed based on stakeholder categorization adapted from Dente [22]. Furthermore, their relations were investigated and represented on a power-interest matrix [23]. The complete analysis can be seen in Konjaria-Christian et al. [24]. The analysis provided insights into how stakeholders were interrelated in the context of the co-creative design of NbS projects and allowed identifying elements of success and failure in stakeholder participation. Based on these experiences, the paper identifies and discusses the main positive factors and challenges from (1) a procedural and methodological point of view and (2) concerning stakeholders' experiences. This discussion is grounded in the context of existing regulations and novel concepts for citizens' participation in urban decision-making processes.

\subsection{General Description of the Project Area}

The Free Hanseatic City of Hamburg (FHH) is one of the three city-states in the Federal Republic of Germany, with almost 1.9 million people, and has recently experienced rapid population growth [25]. The pilot area of CLEVER Cities in Hamburg is located in the district council of Hamburg-Harburg in the urban district of Neugraben-Fischbek (NF), located in the south-west of Hamburg, close to the border to the Federal State of Lower Saxony. It is the largest urban district among the 17 urban districts of Harburg in terms of surface and inhabitants [26]. The project area stretches from the center of the neighborhood of Neugraben to the new development area of Vogelkamp in the east and from the Fischbek-Falkenberg district school and old village structure to the Sandbek residential area in the west. The project area includes both existing settlements and new development areas. Additionally, the project area is surrounded by two nature reserves: Fischbeker Heide and Fischbeker Moor (Figure 1). 


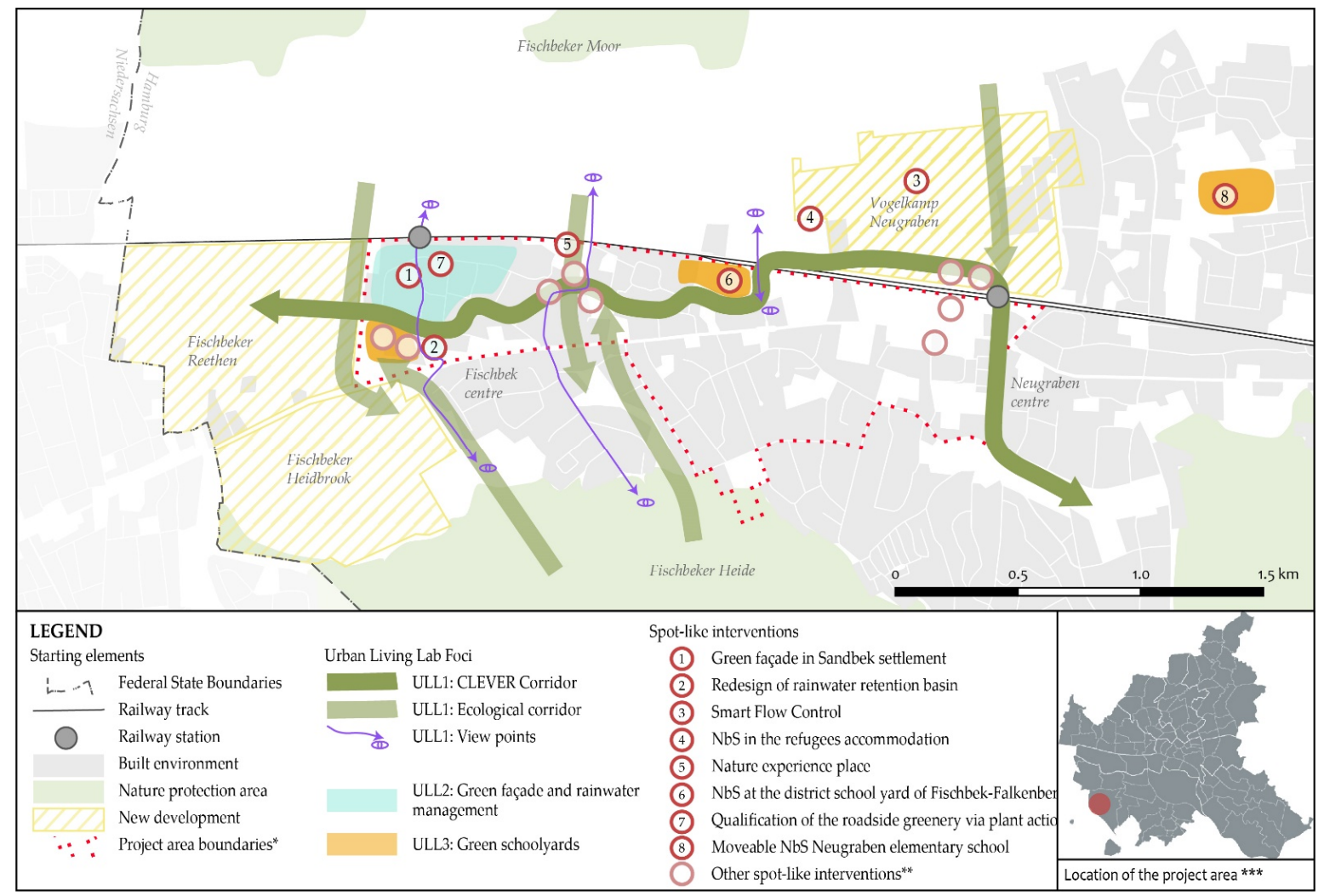

Figure 1. The CLEVER Cities project area in Hamburg. * Project area boundaries as defined in the CLEVER Cities Grant Agreement. ${ }^{* *}$ Other spot-like interventions that are part of the CLEVER Cities Hamburg strategy but are not mentioned in this paper. ${ }^{* * *}$ Location of the project area [27]. (Own elaboration).

The project area is connected to the city center and the federal transport infrastructure through two local and federal train stations. Social housing developments are mainly located in the western part of the project area. At the time of the CLEVER activities (November 2020), three new large construction developments were under construction at the existing built area's fringe. Due to these new developments, the population is expected to increase in the district by about 40\% [28]. According to the Social Monitoring Plan of 2019 [29], NF is considered to have a low or very low value in terms of social conditions and is therefore eligible for receiving special Hamburg funding for its requalification and further development (Integrated City Development Programme-RISE). Concerning the social structure, it is essential to mention that the refugees' accommodation facility, located in the neighborhood of Vogelkamp-Neugraben, has been included in the CLEVER Cities project activities (point 4 in Figure 1).

Notably, NF presents a distinct social and economic situation by hosting a varied social and spatial mix. In this context, CLEVER Cities decided to implement a range of $\mathrm{NbS}$ initiatives as an experimental pilot to explore the social co-benefits and environmental and economic improvements generated by the implementation of $\mathrm{NbS}$. The simultaneous and reciprocal strengthening of the local community and natural resources constitutes an opportunity to address four urban regeneration challenges: human health and well-being, sustainable economic prosperity, social cohesion and environmental justice, and citizen security.

As Hamburg is a city-state, it is crucial to define the three governance levels involved in the process that will appear in the text. The term "federal level" refers to Hamburg as a federal city-state; with the term "district level," the Harburg district is meant; lastly, the term "local level" implies the urban district of NF.

\section{Results}

According to the framework illustrated in Section 2, the project team was set up in Hamburg before starting the co-creation process. The project team includes the District 
Office of Hamburg-Harburg (DHH), three governmental institutions of the state Hamburg (Senate Chancellery; the Ministry of Environment, Energy, Climate, and AgricultureBUKEA; and the State Agency for Geoinformation and Surveying-LGV), the urban development agency (steg), and three scientific partners (HafenCity University-HCU; Hamburg University of Technology-TUHH; and Hamburg Institute of International Economics-HWWI). An overview is provided in Table 1.

Table 1. Project team members' categorization (Own elaboration).

\begin{tabular}{llll}
\hline \multicolumn{1}{c}{ Institution Name } & \multicolumn{1}{c}{ Level } & \multicolumn{1}{c}{ Type } & \multicolumn{1}{c}{ Resources } \\
\hline DHH & District & Public & Political, economic, legal \\
Senate Chancellery & Federal & Public & Political, legal \\
BUKEA & Federal & Public & Political, legal, cognitive \\
LGV & Federal & Public & Cognitive \\
steg & local & Private & Political, cognitive, relational \\
HCU & Federal & University & Cognitive, relational \\
TUHH & Federal & University & Cognitive, relational \\
HWWI & Federal & Research & Cognitive \\
\hline
\end{tabular}

1 Type of resources according to Dente [22].

The District Office of Hamburg-Harburg (DHH) is the institution responsible for coordinating all project partners and processes and implementing the local interventions. The tasks of the DHH include coordination of the Hamburg interventions and evaluation and further concretization of the project ideas together with partners and UIPs. Moreover, $\mathrm{DHH}$ is responsible for planning processes, contracting third parties to commission project implementation, and keeping a constant dialogue between the parties involved to ensure innovation and co-creation in the design process. The DHH acts as an intermediary for Hamburg interventions both within the district office's administrative departments and for the project's local, district, federal, and international partners. Most importantly, the $\mathrm{DHH}$ is the primary contact concerning issues around the CLEVER Cities project in Hamburg. Presenting and raising awareness on the project at different scales (within the administration and civil society) is one of the DHH work's cornerstones.

The other three governmental institutions represent the federal level of the city-state of Hamburg. Senate Chancellery is the leading international contact point and the coordinator for the entire CLEVER Cities project and is in charge of communicating at the state level. BUKEA is the ministry at Hamburg-level in charge of policies regarding the environment, energy, and climate. Within the CLEVER Cities project, BUKEA is engaged in developing and upscale the environmental strategy learnt from the CLEVER Cities experience at the federal level. LGV holds the georeferenced database and the cadastre land register for the Federal State of Hamburg and provides technical measurements. In the CLEVER Cities project, LGV has the task of developing, implementing, and integrating the urban data platform with new information gathered during the project's lifetime. Though not physically involved with the interventions at the local level, they contribute substantially with their specific expertise on particular aspects of the NbS interventions, and they represent the direct link to the federal level.

The local development agency, steg, runs an on-site district office in the project area to improve visibility through various activities promoted at the local level in recent years. The local presence of steg is of significant importance, especially regarding co-creation processes and citizen participation for the various project activities.

Lastly, the three research institutions involved support the local activities with their scientific competencies in urban planning, policies, and landscape architecture (HCU), environmental technology, energy, and water management (TUHH), and socio-economic studies (HWWI).

\subsection{Initiating the Co-Creation Process}

In 2018, to inaugurate the CLEVER Cities project's activities and ensure visibility among local stakeholders, a large-scale kick-off event was organized by DHH, BUKEA, and 
steg. The event's main intention was to raise awareness about the project's objectives and provide a factual basis for further co-creation steps. The event brought together around 130 people, including citizens and representatives from private and public sectors. An innovative tool for digital participation (DIPAS) has facilitated the process of gathering valuable insights and ideas from the participants, which laid the groundwork for specifying particular interventions within three main Urban Living Labs (ULL) (Figure 2a). The content of each ULL will be briefly presented in Section 3.2.
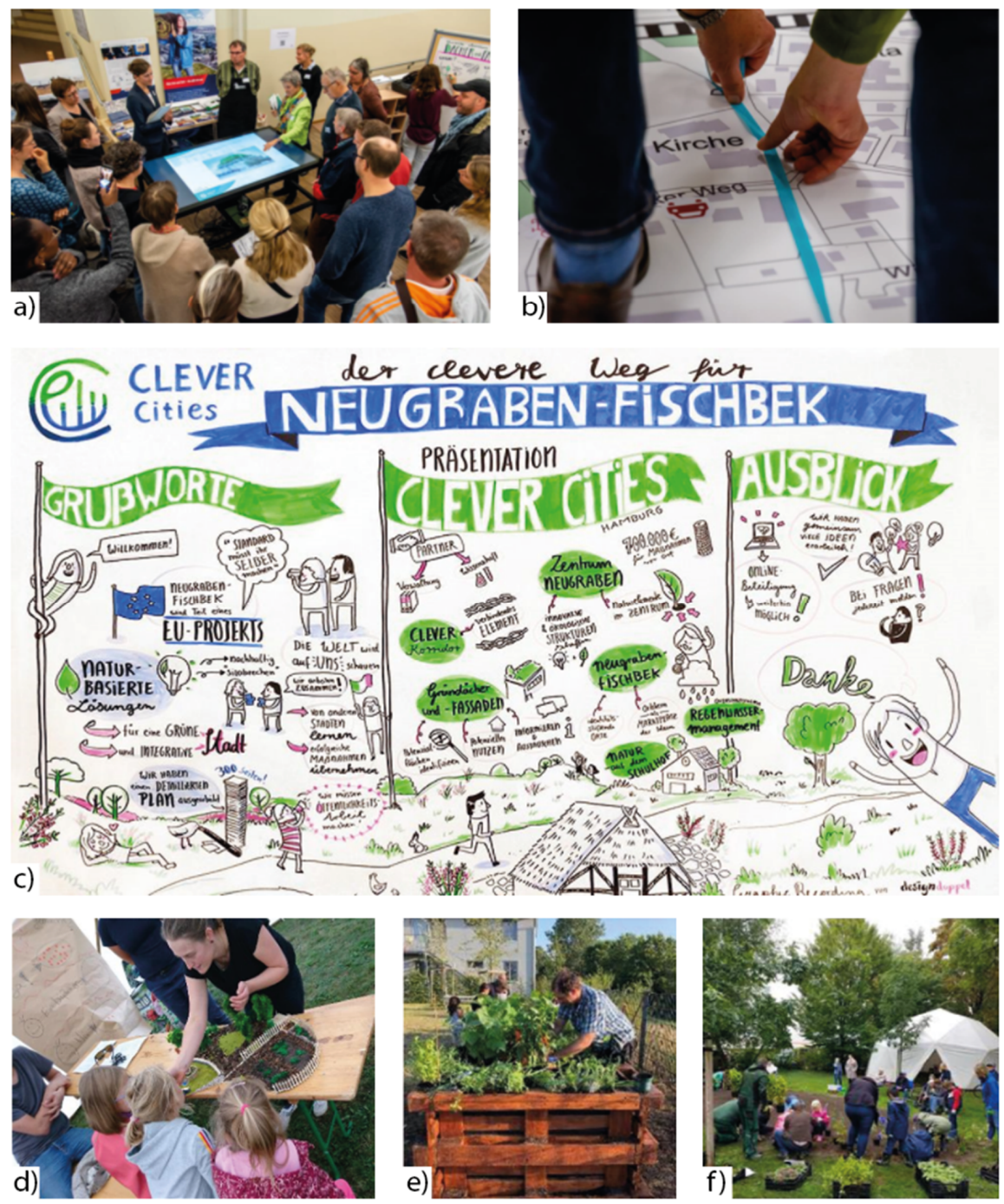

Figure 2. (a) Digital participation system (DIPAS) used in the kick-off meeting (DHH, 2018); (b) carpet with the orthophoto of Neugraben-Fischbek (NF) in the kick-off meeting (DHH, 2018); (c) graphic recording during the kick-off meeting ( $\mathrm{DHH}, 2018)$; (d) model of the garden in the school FischbekFalkenberg built with pupils and teachers (steg, 2019); (e) high bed realized by refugees (steg, 2019); (f) planting action in the Sandbek settlement (steg, 2019).

The DIPAS tool has been used not only during the event day: it was also available online a few weeks after, allowing for further contributions from the local population to the co-creative process. Additionally, a huge carpet representing the Neugraben-Fischbek urban district's orthophoto was used as a basis for further discussion and commenting during the inaugural event (Figure 2b) and other events (district festival Neugraben). Another addition to the event was the graphic recording of the event and its results (Figure 2c).

After the kick-off event, the work in each ULL started with defining the local UIPs. The definition of the local UIP is denoted as phase 1 (i) in the Co-Creation Pathway of 
Morello et al. [30]. Depending on the intervention types, the UIPs were organized into various formats, such as jours fixes, workshops, and multilateral or bilateral strategic planning meetings. UIP meetings have been carried out in face-to-face format, and online meetings due to Covid-19 restrictions and dynamically adapted depending on the specific steps and goals of each ULL. Generally, the DHH initiates the UIP formation process and accompanies it throughout its development, supported by the other project team members.

During the initiation phase of the local UIPs, the project team applied the Theory of Change (ToC) method. The ToC meeting brought together the main interested local stakeholders in defining visions and incremental outcomes needed to achieve the visions set for each ULL under the moderation of the project team.

In September 2019, the project team organized its first annual UIP event, which registered around 140 participants. The meeting took place simultaneously at three different locations throughout the project area, strategically selected to implement $\mathrm{NbS}$ using a handson approach. As an example of the activities conducted, pupils were involved in building a physical model of their ideal school garden (see Figure 2d); in another location, young and old representatives were brought together for a planting action project (Figure 2f).

Additionally, the co-creation process within CLEVER Cities was not limited to the activities conducted in the three ULL. The project team brought the CLEVER Cities project's experience to other external activities and events, aiming at broader participation. Of particular importance, during the urban district festival "Neugraben Erleben," the "SensafetyApp" was presented by LGV [31]. It is a mobile application that allows users to evaluate specific locations in the project area based on their subjective impressions and perceptions of safety. The citizens' participation via the "Sensafety-App" defines one of the integral elements in the co-monitoring phase (iv).

\subsection{Co-Creation Processes in Hamburg}

The following paragraphs describe the implemented projects in Hamburg for each of the three ULL, with a particular focus on the co-creation process, which included the previously mentioned co-creation phases "UIP establishment ${ }^{* \prime \prime \prime}$ (i) and "co-design"(ii) with their respective stakeholders, procedures, and tools. Three different focus topics have been defined for the project area: (1) a green corridor (ULL 1), (2) green roofs and façade, and rainwater management (ULL 2), and (3) green schoolyards (ULL 3).

Funding opportunities from the Horizon 2020 Program are covering interventions and activities within the project timeframe, demanding for taking decisions towards enabling mechanisms of ownership building for future maintenance for both technical solutions, such as aquaponics (Section 3.2.2) and social solutions, such as the high beds constructed together with refugees (Section 3.2.1). Notably, because of the COVID-19 situation, alternative participation tools had to be considered to continue the co-creation processes.

\subsubsection{Focus-“CLEVER Corridor" (ULL 1)}

The "CLEVER Corridor" aims to establish a connection among several NbS interventions spatially spread across the CLEVER Cities project area (Figure 1). The interventions have a broad objective of connecting the two surrounding nature conservation areas with a potential bridging function. The connection effort was translated into a set of small interventions developed organically under the corridor's frame. A guiding system that will be co-created with diverse stakeholders and inclusive formats, such as workshops, will function as a recognizable sign for the corridor. Private and public entities and individual citizens were strongly involved. The CLEVER Corridor will reciprocally link all these diverse spot-like interventions and will emphasize and highlight the existing path connections between the two nature conservation areas. This ULL consists of two levels: the individual spot-like interventions and the guiding system that creates the umbrella for all projects. Therefore, co-creation in this ULL is organized in multiple UIPs established in phase 1 (i) of the co-creation process. The UIPs within the focus topic "CLEVER Corridor" are practicing and representing diverse forms of collaboration between local 
stakeholders, private entities, the public administration, and universities and signal the active participation of different social and age groups in many actions along the corridor. Another intervention within the corridor's scope is the "nature experience place" project coordinated by the public management office department of DHH and facilitated by a landscaping architecture company. In this case, face-to-face participation during the codesign phase (ii) was complemented by online participation due to COVID-19 prevention regulations. For this purpose, the project team used the DIPAS tool supported by LGV and local NGOs, where citizens for three weeks had the opportunity to directly participate in the planning by choosing their favorite options of natural elements.

In the context of the "CLEVER Corridor" ULL, it is worth mentioning that the project also realized a collaboration with the refugee accommodation facility close to the new development area Vogelkamp-Neugraben (Figure 1). With the facilitation of steg and the help of translators, in the co-design phase (ii), ideas for designing mobile elements for the common exterior area of the accommodation were collected from the refugees via workshops. Successively, under the guidance of steg and the facilitation of the manager of the refugees' accommodation, refugees were involved in the co-designing (ii) of multi-purpose islands with seats and planting areas constructed out of timber and destined as places for gathering and entertainment. Additionally, this participatory process involved refugees in the third phase of co-implementation (iii) (construction and planting) of the high beds to transform the area into a place that "invites them to stay" (Figure 2e). A local NGO and a carpenter were supporting the construction works. Figure 3 shows the stakeholders' constellation in ULL 1.

ULL 1: CLEVER Corridor

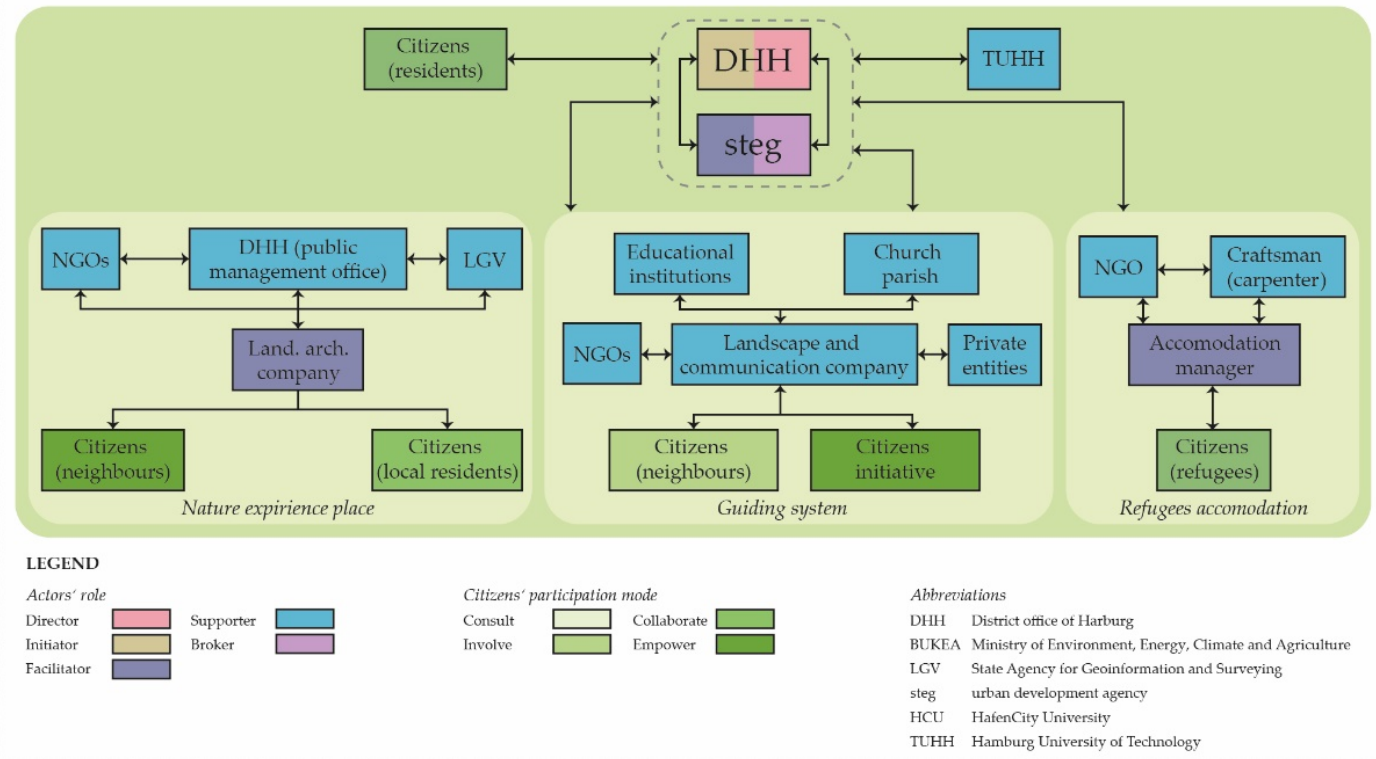

Figure 3. Representation of the stakeholders' constellation for Urban Living Lab (ULL) 1. Roles were adapted from Dente [22] (see Supplementary Material A for definitions). Roles of citizens refer to the degrees of participation according to Morello and Mahmoud [32] based on Arnstein [33]. This graph has to be understood as a simplified representation of a more comprehensive and complex stakeholder constellation. The stakeholders represented here are the project team members and the main stakeholders involved in the local urban innovation partnerships (UIPs). The constellation represented here is the one that can activate and bring on board other stakeholders for achieving the vision defined in the Theory of Change (ToC) process.

\subsubsection{Focus-“"Green Roof and Façade, and Rainwater Management" (ULL 2)}

The focus of ULL 2 consists of two main pillars: (a) implementation of green roofs and façades, and (b) rainwater management. Interventions include the greening of a noise barrier at the train station Neugraben and installing a green façade in the Sandbek residential area. The co-creation process covers various activities, such as the ToC workshop 
with the federal housing company's participation and continuous monthly meetings with project partners and Integrated City Development Programme (RISE) representatives. Throughout the period marked by strict COVID-19 prevention regulations, informational letters were sent to the residents via mail. However, on-site events (e.g., the planting action of the façade) needed to be postponed to the future.

Furthermore, awareness-raising measures regarding green roofs and façades funding possibilities have been carried out. During the annual UIP event, information about funding opportunities has been disseminated thanks to the direct involvement of BUKEA. Furthermore, press releases were issued, and additional informational material was disseminated during the urban district festival (see Section 3.1).

Building greenery is also closely related to the second pillar within ULL 2-an analysis of the Neugraben-Fischbek area's vulnerability against heavy rainfall events. The concept that will be developed based on this analysis is innovative per se, as it will be applied at the entire urban district Neugraben-Fischbek, a new scale for conducting such analysis in Hamburg. The co-creation framework has brought together many stakeholders, from the public sector to academic representatives. The local UIP members are meeting regularly through online sessions wherein the progress and next steps are discussed.

Concerning the rainwater management topic, two more projects need to be mentioned. The collaboration with the Hamburg Water management company (Hamburg Wasser) has succeeded in a pilot project using innovative Smart Flow Control (SFC) technology [34]. The public-private collaboration project is planned to be tested on a ca. 10 sq.m green roof to further optimize the retention capacity and application-controlled release and discharge water into the sewer system. Another part of the ULL 2 envisions redesigning a rainwater retention basin by building a retention soil filter. The co-creative process will see the involvement of Hamburg Wasser and landscape architecture studios under the guidance of steg and HCU. Figure 4 shows the stakeholders' constellation in ULL 2.

\section{ULL 2: Green Roof and Façade, and Rainwater Management}

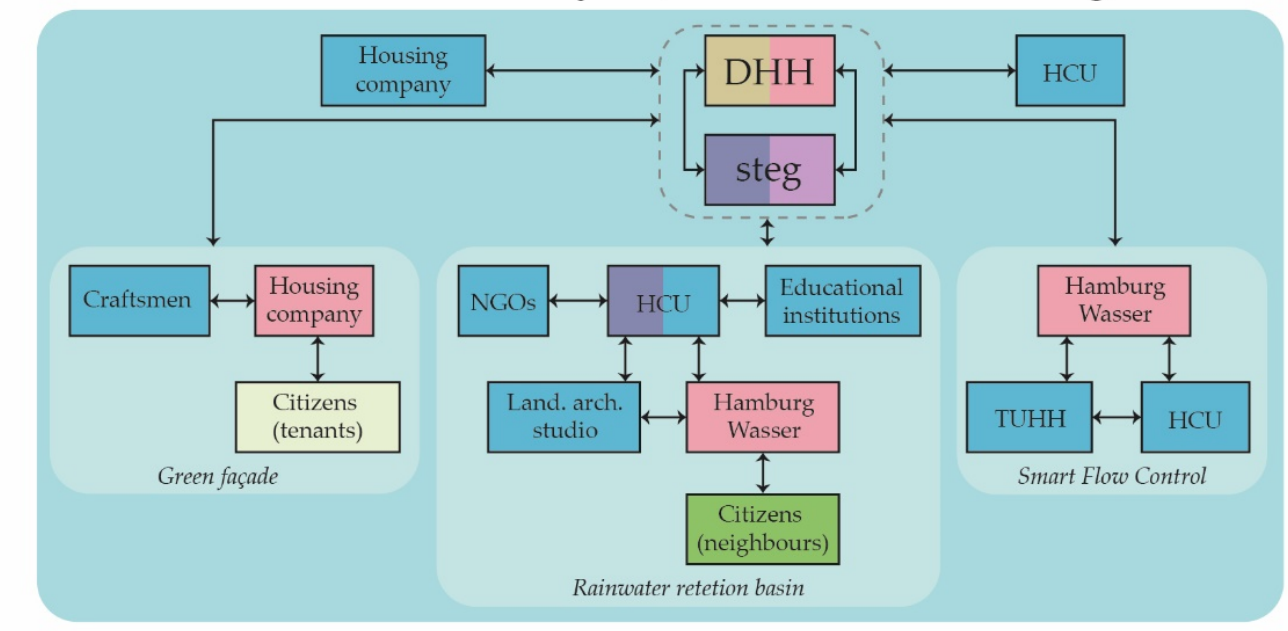

LEGEND

Actors' role

Director
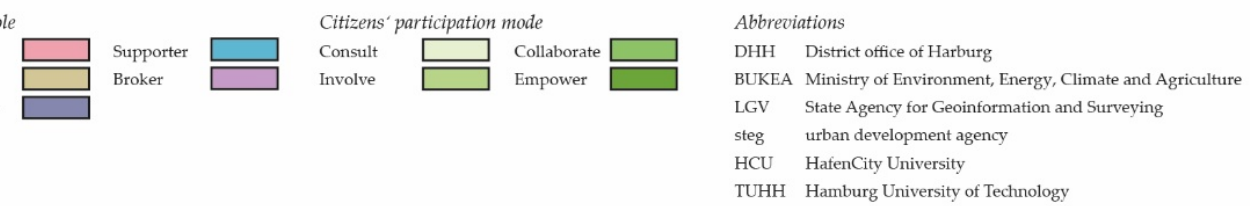

Figure 4. Representation of the stakeholders' constellation for the ULL 2. Roles were adapted from Dente [22] (see Supplementary Material A for definitions). Roles of citizens refer to the degrees of participation according to Morello and Mahmoud [32] based on Arnstein [33]. The stakeholders represented here are the project team members and the main stakeholders involved in the local UIPs. The constellation represented here is the one that can activate and bring on board other stakeholders for achieving the vision defined in the ToC process. 


\subsubsection{Focus-“Green Schoolyards" (ULL 3)}

The third ULL is fostering the redesign of schoolyards located in the project area. At the beginning of the co-creation process, a workshop was held in the district school of Fischbek-Falkenberg to gather innovative ideas from pupils, parents, and teachers. The school staff is taking the lead in the process, which is planned to be further replicated by at least one other school in the project area. Planned interventions include the so-called researchers' garden that combines the curriculum with gardening and outdoor activities and the realization of aquaponics.

One of the participating schools (Neugrabe elementary school—point 8 in Figure 1) introduced a specific challenge for $\mathrm{NbS}$ implementation into the project because the school and its yard will be completely renovated in the coming years. New elements included in the schoolyard will be therefore positioned only temporarily. Hence, participants of the co-creative process were engaged to think about mobile and temporary NbS. The local UIP is composed mainly of the schools' administrations, the school building company, a teacher, pupils, CLEVER project partners (steg, $\mathrm{DHH}$, and $\mathrm{HCU}$ ), and students of the architectural faculty HCU. The solutions developed in the actual school shall be an excellent example for other schools in the urban district to undertake $\mathrm{NbS}$ projects with a dedicated focus on sustainability. Plans developed during the co-design process will be realized together with teachers, pupils, and parents, and with the help of steg in 2021. The ULL 3 activities are supported by an increase in teaching hours linked to environmental aspects, including sustainability topics in the school curriculum. Figure 5 shows the stakeholders' constellation in ULL 3.

\section{ULL 3: Green Schoolyard}

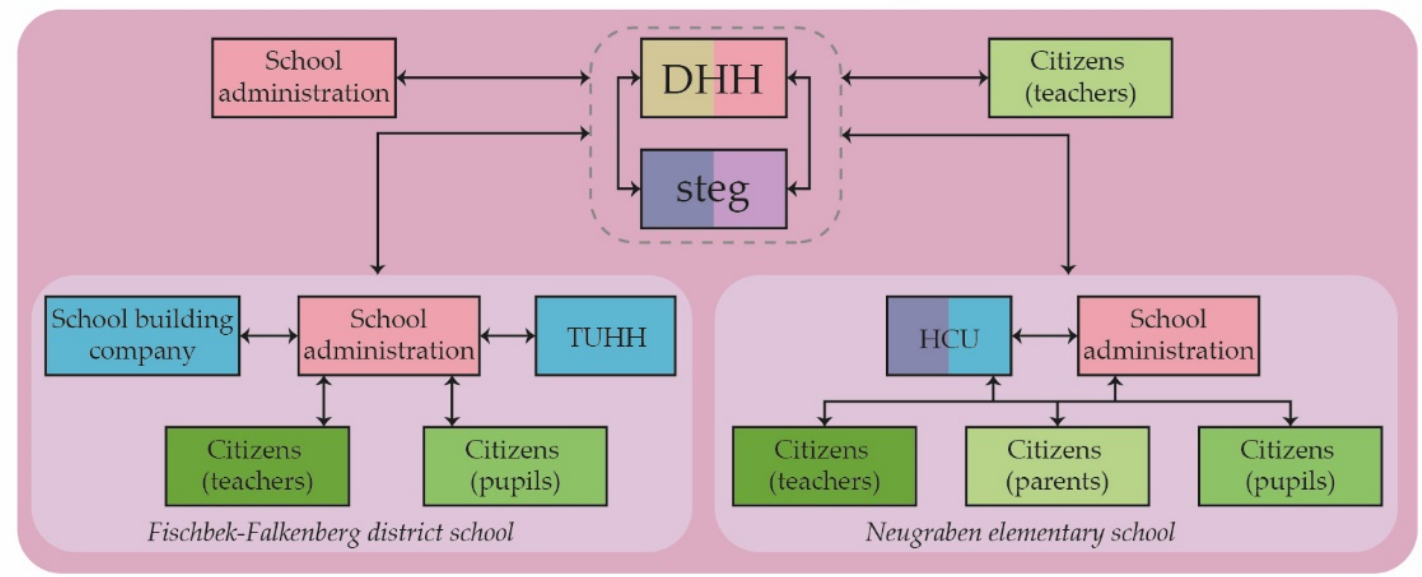

LEGEND

Actors' role

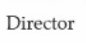

Initiator

Facilitator

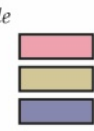

Supporter

Broker

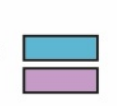

Citizens' participation mode

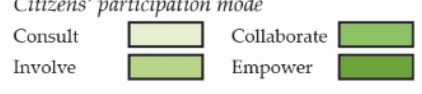

Abbreviations

DHH District office of Harburg

BUKEA Ministry of Environment, Energy, Climate and Agriculture

LGV State Agency for Geoinformation and Surveying

steg urban development agency

$\mathrm{HCU}$ HafenCity University

TUHH Hamburg University of Technology

Figure 5. Representation of the stakeholders' constellation for the ULL 3. Roles were adapted from Dente [22] (see Supplementary Material A for definitions). Roles of citizens refer to the degrees of participation according to Morello and Mahmoud [32] based on Arnstein [33]. The stakeholders represented here are the project team members and the main stakeholders involved in the local UIPs. The constellation represented here is the one that can activate and bring on board other stakeholders for achieving the vision defined in the ToC process. 


\section{Discussion}

This section identifies and discusses the main results of the co-creation experience in the Hamburg case study and their challenges regarding stakeholders' participation.

As explained in Section 3.2, various procedures and methods have been used to manage the different phases of the co-creation process. Since only the first two steps (i) and (ii) of the Co-Creation Pathway have been discussed, procedures, methods, tools, and stakeholder experiences deployed during these phases are analyzed. The first part of the discussion will concentrate on procedural and methodological issues in the first two co-creation phases, and the second part will analyze the stakeholder constellation and its implications during these phases. Lastly, recommendations are considered. Figures 3-5 represent the stakeholders and their constellation within the three ULL synthetically.

It is essential to mention that the commitment towards the EU commission and the strict allocation of funds as an incentive to apply the process is not to underestimate and brought the adoption of individual specifications and principles, such as the use of the $\mathrm{NbS}$ concept as a strict requirement. However, the network built during the process is expected to continue for the project's duration and even beyond. This is also obtained by establishing new and strengthening existing stakeholders' networks and applying formal and informal instruments.

\subsection{Procedural and Methodological Aspects of NbS Co-Creation in the Hamburg Case-Study}

Regarding the co-creation process of NbS, the systematic application of the Theory of Change (ToC) [17] guaranteed a particular path dependency of the co-creation process, which translated in a rigid but structured logic. As mentioned in Section 3, the application of ToC guided the project team and the stakeholders involved from a common understanding of the problems towards a shared definition of the objectives. Especially the inherent common sense of the ToC approach helped to structure the process. Additionally, it favored an easy understanding of the process itself also from the participants' perspective. In fact, the passage between steps is based on understanding how and why certain activities produce effects on the local context [35] and drives towards the resolutions of eventual challenges encountered. In Hamburg, the ToC process resulted in the visions and outcomes that currently guide local stakeholders in their activities on site. Further, the ToC workshop results have been fed into the co-monitoring phase (iv) of the $\mathrm{NbS}$ implemented in the project area.

For the co-creation process, the local UIPs played a core role as experimental interventions. They have been established for different interventions, and each case was composed of a varying set of stakeholders. Additionally, the focus area of the corridor of ULL 1 requires many different stakeholders and combinations from ULL 2 and ULL 3. Mostly classical formats like workshops and meetings to bring together the stakeholders were chosen and adapted to co-creation principles. With this, it is essential to mention that Hamburg's stakeholders had already experienced co-creation approaches through the RISE program. Hence, previous experiences have facilitated the implementation of the project framework.

Concerning the co-creation formats, the participation formats deployed in the schools (ULL 3) were suitable for catching pupils' attention for the project activities and objectives to raise their awareness for $\mathrm{NbS}$ specifically and sustainability issues in a broader sense. Hence, hands-on workshops to grasp people's attention and integrate them into the development processes revealed their potentials in Hamburg's case.

Nevertheless, the concept of $\mathrm{NbS}$ is mostly founded on capacity building and bottomup participation (e.g., [7] p. 14) in the conviction that only participation-based processes can raise awareness on complex topics such as sustainable development (see [36]). Accordingly, a shared definition of common objectives plays a relevant role in the next steps of the $\mathrm{NbS}$ development process. Lastly, the ULL approach was addressed as a challenge in terms of time and resource deployed: especially, bringing together local, district, and federal stakeholders required specific facilitation and coordination competencies. Nonetheless, the 
organizational process has resulted in more vital and more solid networking among the key stakeholders.

The integration of the Living Lab approach with a large event format, on the one hand, provided updates cyclically on the project and allowed citizens to get informed on the current initiatives and to contribute with different ideas and suggestions (as in the kick-off event). On the other hand, organizing and steering such a process required a considerable investment of time and human resources: activities must flow across scales in a continuous effort of communication and decisional steps, investigating and deepening each element and their interconnection [35]. Nevertheless, the two big events organized in Hamburg were useful for two reasons: increasing the project's visibility to the broader public (130 and 140 participants respectively) and synthesizing the work done so far.

The several moderation tools and methods deployed along the co-creation process were advantageous, particularly the online-tool DIPAS, the orthophoto-carpet, and the graphic recording. Additionally, the Hamburg CLEVER Team has deployed a combination of traditional and innovative tools to facilitate knowledge transfer and support the discussion along the process. The DIPAS tool, with its participatory data-table, was used in the kick-off event to collect stakeholders' opinions and visualizing issues within the project area. The advantage of using such digital participation tools is that all identified issues are immediately linked to geo-data coordinates. After the event, the conversion of stakeholder comments into a digital format was more straightforward and less time-consuming. Therefore, this tool's use led to reduced operational costs and time within the stakeholder participation processes. DIPAS was further used on a second occasion to support citizen participation in the nature experience park along the corridor in ULL 1.

As a further tool, the carpet realized with the orthophoto of Neugraben-Fischbeck was applied successfully during the kick-off event in autumn 2018 and at the district festival "Neugraben Erleben" in 2019. It attracted people to express their interests and issues in the project area: in fact, a carpet of such size catches people's eye and animates them to participate. Therefore, it was regarded as a useful tool for stakeholder activation during phase (i) of the co-creation process.

Lastly, the graphic recording of the discussion was useful to depict the outputs of the meeting visually and, at the same time, create a recognizable design for the participants.

\subsection{Stakeholder-Related Aspects of NbS Co-Creation in the Hamburg Case Study}

Co-creation requires managing the challenge of engaging local stakeholders to listen to all opinions and empower them to participate in policy-making actively [37]. Concerning policy-making, individual stakeholders' role is discussed in the next subsection concerning their constellations and experiences within the project activities.

Firstly, in a co-creation process, the local stakeholders' network has to be created and, secondly, to be maintained. This includes the management of the various activities conducted. While many scholars claim that local public authorities do not have power or interest in this sense (see [21]), the situation for Hamburg was somewhat different due to the central role of co-creation for the CLEVER Cities project around which the project team organized all other activities in the first two analyzed phases (i) and (ii).

Additionally, the kick-off event format with the large-scale participation created a favorable environment for the citizens to play a central role in defining the topics to debate upon [8]. Concerning the refugee accommodation facilities, the activities developed together with the residents resulted already in physical interventions (see Section 3.2.1). As a result, engagement is one of the critical elements of the NbS design process, as previously discussed.

The district public administration thus functions as initiator and coordinator of the entire process, and it was one of the main stakeholders having interests in the success of the initiatives put in place by the CLEVER Cities project (Figures 3-5). It has the authority to initiate and foster co-creation activities within its project partner capacities and by subcontracting third parties or directly commissioning works entailing the planning, realization, 
and implementation of different project co-creation activities. With various stakeholders' involvement, the coordination, supervision, and approval of the commissioned work rested with the district public administration, which remained de facto always indirectly involved. In this way, the respect of the co-creation principles can be guaranteed if the administration is backing them. Meetings within the project team were held regularly to update on the status of the various interventions.

Additionally, the district public administration participated in several political committee meetings at the district and city level, where the CLEVER Cities project and its activities were documented. However, multiple spot-like interventions, tailored co-creation approaches for these interventions, diverse stakeholders with different institutional settings and experiences, and multilateral agreement rounds for fine-tuning the processes in some cases lead to lengthy procedures and a high workload [38]. Furthermore, since the budgetary authority rested with the district public administration, together with the coordination role and the communication activities with the Hamburg partners as well as internationally in the overall project consortium (cf. [39] p. 14), its decisional power resulted in being very relevant, compared to the other partners. However, the political constellation's multi-level character in Hamburg puts the district public administration in a constant dialogue with the Hamburg ministries level.

The BUKEA contributed with scientific expertise on the natural environment and provided support from and within institutional levels. The Ministry shares a political interest at a city-wide level, being in charge of green roofs strategy while being engaged through CLEVER Cities at the local level (see ULL 2). One of the benefits of having the different city authority levels on board is the potential for upscaling the districts' results to the city-level (vertical integration) and, similarly, its transfer to other districts (horizontal integration).

Having an urban development agency being physically present in the area allowed the project activities to be adequately spread among the residents. Organizing events and attracting people to participate were not the only advantages; also, the profound knowledge of the local (social) situation and their agency's daily contact with citizens were crucial elements for the success of the initiatives (see the role of "Broker" in Busetti and Vecchi [40]). Indeed, the presence of an intermediary organization active in citizen involvement at the local level and knowing some of the most important local stakeholders in person has proved to be fundamental in establishing a stakeholder network in the urban district. This helped the project team in several situations to get into contact with key players and to solve conflicts. Nevertheless, the local development agency's inner knowledge and moderation skills were considered substantially useful for raising awareness on $\mathrm{NbS}$ among local stakeholders and citizens and contributing to capacity-building processes.

Furthermore, the co-creation process was largely supported by scientific partners' involvement, both federal and international. While the structure of the framework was provided by the international project partners (UIP, ToC, Co-Creation Pathway), the federal research institutions were in charge of adapting it to the local context and translating the general framework instructions to the specific implementation level. Steering activities, data collection, and analysis of the ToC workshops' results were carried out with the help of the federal scientific partners. The practicality degree was also challenging throughout the project while providing sparks for reflections based on real case implementation. Nevertheless, the involvement of scientific partners facilitated the further elaboration of the main results to be coupled with a broader context and to be able to respond with novel and sound scientific background to the local challenges encountered.

\subsection{Recommendations}

Based on the aspects discussed in the previous subsections, some critical issues for $\mathrm{NbS}$ co-creation organization can be derived, comprising the horizontal and vertical dialogue, the essential characteristics of the stakeholder constellation, and the presence of an overarching guiding framework. 
According to the contract signed with the European Commission, the project team initiated the complex participation and implementation process. The public administration played a steering role, among others, because it holds an intermediate position, guiding and supporting the initiatives on the ground and participating at the strategic level. The guiding role often signifies that the public administration plays a central role in the cocreation process. On the local side, the local development agency has been working in many directions, e.g., as a coordinator of the local activities in the urban district, as a mediator between local stakeholders and the district public administration, and as a facilitator for enhancing social inclusion. Since the administration was involved in all processes, it was perceived as close to the citizens' challenges and wishes. The district public administration's leading role in the initiation and coordination of co-creative processes has proven to be beneficial. However, it was only through close cooperation with the urban development agency that residents could be reached and co-creative processes carried out. Therefore, it is highly recommended to combine one planning (public administration) and one implementing body (local development agency) to implement co-creative processes.

The establishment of such cooperation opened up new involvement opportunities and enriched the process with additional ideas. In this sense, communication was particularly relevant in Hamburg, with the scope of informing and involving the broader public and requiring a continuous adaptation to search for a common and understandable language. Additionally, to achieve the desired outcomes defined through the co-creative process, it was necessary to establish dialogues and cooperation not only across administrative levels [41] (p. 26) but also within the institutions themselves [42]. This cross-sectoral dynamic is revealed to be of enormous importance to reaching the project's objectives concerning the inherent characteristics of $\mathrm{NbS}$, which requires a certain degree of interdisciplinary, cross-sectoral cooperation and a broader view of the local challenges. Barriers could be overcome by establishing contacts, building relationships, subscribing to formal and informal cooperation formats. To some extent, changes to correct the process trajectory were envisioned and enabled by facilitation tools.

Concerning the role of civil society and academia, the entire process should be conceived to let citizens and, most importantly, disadvantaged social groups play a direct role in the implementation. This direct involvement that will be translated into co-implementation activities in the next phases of the project fosters the sense of ownership of the various co-implemented interventions and further maintains their interest to continue to take care of these interventions after their realization. Direct involvement also contributes to a certain degree of empowerment. The process's learning effects are fundamental to continuity in applying co-creation activities at the local level. Thus, thanks to the first-hand experience in dealing with $\mathrm{NbS}$ through hands-on workshops, it can help enhance the understanding of such complex topics to the general public. In this sense, the workshops serve as a knowledge transfer tool.

Generally, combining the several local aggregation and meeting formats (local UIPs) with the more comprehensive and outreaching annual UIP events can be considered a reasonable practice. This integration was useful for connecting the various local interventions under a broader and shared vision and informing and mobilizing a broader and more diverse group of people, thus enhancing the potential for creativity in the intervention design. Furthermore, it helps gather and synthesize the work conducted locally in a presentable way for dissemination and visibility purposes.

Working with citizens usually entails a more significant effort to prepare the various steps within the co-creation process. The timing and content of communication with stakeholders affect their willingness to participate. Keeping their interest high and showing the results coming from the discussions regularly increases motivation. Further, laypersons' involvement requires finding suitable communication formats, instruments, and wording where all can meet and agree upon, which should avoid reaching only certain groups and excluding others. The risk of excluding specific participant sets is amplified when working with vulnerable social groups, such as in ULL 1. Starting the dialogue with the 
refugees requires more extended and more careful preparation. Besides the necessity of hiring translators for various languages, the main challenge is to awaken their interest in a place where they presumably intend to live only temporarily (e.g., opened in 2016, the refugee camp in Vogelkamp- Neugraben is planned to be closed by 2026).

In the current scientific discourse, co-creation processes are discussed as a potent tool to sustain the development of $\mathrm{NbS}$ through the involvement of all social groups $[7,42]$ when addressing sustainability and resiliency in cities. The Co-Creation Pathway provides a guide for consistent implementation of this process yet allowing for adjustments when applied at the local level as presented in [14,30]. In Hamburg, the adaptation of the Co-Creation Pathway to the local context was facilitated by the scientific institutions by a broader involvement of civil society and other social groups in addition to the usual suspects [21]. As previously mentioned, communication and conflicts were fundamental for achieving the project's objectives because they helped reach new levels of knowledge and understanding of sustainable urban development and the role of NbS. The continuous integration of local knowledge, the support from academia, and the business sector's involvement create a potent base for developing further the initial ideas of a project. Improved organization and participation strategies include providing a foundation for a discourse, collecting examples to implement possible ideas, and proposing alternative and ad hoc approaches $[4,37]$. This is achieved due to a mutual and constant dialogue with the local partners and agreement on project continuation.

\section{Conclusions}

This paper provided insight into the current situation (November 2020) of the advancement of the $\mathrm{NbS}$ interventions achieved in the CLEVER Cities project in Hamburg and the interplay of the several stakeholders that contributed to the process. Hence, the analyses conducted to draft this paper refer to the interim project results. Nevertheless, some relevant outcomes can be derived to continue the work within the CLEVER Cities project timeframe and for the scientific discussion on stakeholder involvement in planning and designing $\mathrm{NbS}$ and some thoughts for their implementation.

Given the intrinsic multi-dimensionality of NbS, they can be identified to address complex issues characterized by uncertainty and interdependence. $\mathrm{NbS}$ are claimed to answer several current societal challenges [43], and foster local economies and allow inclusion simultaneously [7]. According to a co-creative model, the CLEVER Cities project's answer to this complexity is to bring various views, knowledge, and areas of expertise under the same roof.

As discussed, the project team gathered representatives from a wide range of backgrounds (Section 3.1), complemented by the sectorial expertise of the different stakeholders involved that suited the best specific interventions. It is possible to notice that the project team is frequently present as a core stakeholder within the ULL (Figures 3-5). These are the district public administration and the local development agency: for legal, political, and economic resources, the former; for proximity with the local population and experience with co-creation processes, the latter. These two stakeholders had to overview all activities being conducted and punctually activate the necessary stakeholders to address specific challenges of the selected areas of intervention.

The co-creation processes [18] (p. 273) might be a difficult and tortuous path, implying a considerable amount of time and resources to dedicate to its sustainment. Instruments and cooperation modes are critical and should not be underestimated. Concerning the Hamburg experience, it can be stated that the co-creation process benefited from the support of an overarching strategy. As an additional benefit, co-creating the NbS contributed to generating a learning effect among the participants. From the point of view of the cocreation approach's resilience in the case-site, it became apparent that formal and informal cooperation mechanisms have to be considered early in the process and should outlast the research project's duration reach a self-sustaining state. 
The case study experiences showed that the experimental approach of research-based interventions could lead to new insights that will transform the existing governance settings. Hence, the co-creation principles that sustain the $\mathrm{NbS}$ development effort are demanding a restructuring of the decision-making processes by learning from the approaches mentioned above and becoming common practice (see [44,45]). The enlargement of participatory design solutions includes foreseeing a certain degree of flexibility, which allows reacting to problems, offering alternative solutions, and deploying different mechanisms to connect, commit, and share decision-making power with ad hoc governance models.

The described co-creation activities, the chosen pathway, and the involved stakeholders can be taken as examples of how $\mathrm{NbS}$ co-creation can be steered, supported, and facilitated. It was recognized that the $\mathrm{NbS}$ topic is of great interest among the different social groups and contributes to uniting people while achieving beneficial results for their neighborhoods and cities [8]. Additionally, district public administrations fostering the $\mathrm{NbS}$ idea can profit from enhanced visibility in the district and resulting benefits from new networks within and beyond the authorities' boundaries.

All this said, by addressing governance and decision-making structures, bringing together different expertise in the joint effort to address significant societal challenges, $\mathrm{NbS}$ are claimed to unlock potential for building resilient cities and fostering more shared sustainable development.

Supplementary Materials: The following are available online at https:/ / www.mdpi.com/2071-105 $0 / 13 / 5 / 2572 /$ s1.

Author Contributions: Conceptualization, A.A., A.R., S.K.-C., and J.K.; methodology, A.A. and A.R.; writing - original draft preparation, A.A., A.R., and S.K.-C.; writing-review and editing, A.R., S.K.-C., and J.K.; funding acquisition, J.K. All authors have read and agreed to the published version of the manuscript.

Funding: This research was funded by the European Union's Horizon 2020 innovation action program under grant agreement number 776604.

Institutional Review Board Statement: Not applicable.

Informed Consent Statement: Not applicable.

Data Availability Statement: The data presented in this study are available on request from the corresponding author. Data are taken from Konjaria-Christian et al. [24]. The data are not publicly available due to the internal character of the deliverable.

Acknowledgments: This work has been presented at the Greening Cities Shaping Cities Symposium in October 2020 (https:/ / www.greeningcities-shapingcities.polimi.it/ accessed on 18 November 2020). The work was prepared in the framework of the European Horizon 2020 project Clever Cities. Herewith, the authors would like to thank Jan Pastoors (DHH) and steg Hamburg mbH for their comments and suggestions for the draft and the provision of information related to local stakeholders and activities; and Fabrizio M. Amoruso from the Sustainable Architecture Integrated Design Lab of SKKU (Republic of Korea) for his general feedback on the text. Lastly, the authors would like to thank Israa Mahmoud and Eugenio Morello (Politecnico di Milano) as editors of this Special Issue.

Conflicts of Interest: The authors declare no conflict of interest.

\section{References}

1. Maes, J.; Jacobs, S. Nature-Based Solutions for Europe's Sustainable Development. Conserv. Lett. 2017, 10, 121-124. [CrossRef]

2. Biermann, F. The future of 'environmental' policy in the Anthropocene: Time for a paradigm shift. Environ. Politics 2020, 21, 1-20. [CrossRef]

3. Mahmoud, I.; Morello, E. Co-Creation Pathways as a catalyst for implementing Nature-based Solution in Urban Regeneration Strategies: Learning from CLEVER Cities framework and Milano as test-bed. Urban Inf. 2018, 278, $204-210$.

4. Frantzeskaki, N.; McPhearson, T.; Collier, M.J.; Kendal, D.; Bulkeley, H.; Dumitru, A.; Walsh, C.; Noble, K.; van Wyk, E.; Ordóñez, C.; et al. Nature-Based Solutions for Urban Climate Change Adaptation: Linking Science, Policy, and Practice Communities for Evidence-Based Decision-Making. BioScience 2019, 69, 455-466. [CrossRef] 
5. European Commission (EC). Nature-Based Solutions: Nature-Based Solutions and How the Commission Defines Them, Funding, Collaboration and Jobs, Projects, Results and Publications. Available online: https:/ / ec.europa.eu/info/research-and-innovation/ research-area/environment/nature-based-solutions_en (accessed on 15 February 2021).

6. European Commission (EC). Nature-Based Solutions Research Policy: EU Research Policy, What Nature-Based Solutions Are, Background, News and Documents. Available online: https://ec.europa.eu/info/research-and-innovation/research-area/ environment/nature-based-solutions/research-policy_en (accessed on 15 February 2015).

7. IUCN. Global Standard for Nature-based Solutions. In A User-Friendly Framework for the Verification, Design and Scaling up of NbS, 1st ed.; IUCN: Gland, Switzerland, 2020; ISBN 978-2-8317-2058-6.

8. Ferreira, V.; Barreira, A.; Loures, L.; Antunes, D.; Panagopoulos, T. Stakeholders' Engagement on Nature-Based Solutions: A Systematic Literature Review. Sustainability 2020, 12, 640. [CrossRef]

9. Frantzeskaki, N.; Kabisch, N. Designing a knowledge co-production operating space for urban environmental governanceLessons from Rotterdam, Netherlands and Berlin, Germany. Environ. Sci. Policy 2016, 62, 90-98. [CrossRef]

10. Kemp, R.; Loorbach, D. Governance for Sustainability through Transition Management. In Proceedings of the Open Meeting of Human Dimensions of Global Environmental Change Research Community, Montreal, QC, Canada, 16 October 2003; (accessed on 26 February 2021).

11. Frantzeskaki, N.; Loorbach, D.; Meadowcroft, J. Governing societal transitions to sustainability. Int. J. Sustain. Dev. 2012, 15, 19-36. [CrossRef]

12. CLEVER Cities. About the Project. Available online: https://clevercities.eu/the-project/ (accessed on 13 September 2020).

13. Bulkeley, H.; Coenen, L.; Frantzeskaki, N.; Hartmann, C.; Kronsell, A.; Mai, L.; Marvin, S.; McCormick, K.; van Steenbergen, F.; Voytenko Palgan, Y. Urban living labs: Governing urban sustainability transitions. Curr. Opin. Environ. Sust. 2017, $22,13-17$. [CrossRef]

14. Morello, E.; Mahmoud, I.; Gulyurtlu, S. CLEVER Cities Guidance on Co-Creating Nature-Based Solutions: PART II-Running CLEVER Action Labs in 16 Steps. 2018. Available online: https://clevercities.eu/resources/deliverables/ (accessed on 3 September 2020).

15. Carayannis, E.G.; Campbell, D.F. Triple Helix, Quadruple Helix and Quintuple Helix and How Do Knowledge, Innovation and the Environment Relate To Each Other?: A Proposed Framework for a Trans-disciplinary analysis of Sustainable development and Social Ecology. Int. J. Soc. Ecol. Sustain. Dev. 2010, 1, 41-69. [CrossRef]

16. Weiss, C.H. Nothing as practical as a good theory: Exploring theory-based evaluation for comprehensive community initiatives for children and families. In New Approaches to Evaluating Community Initiatives: Concepts, Methods and Contexts; Connell, J., Kubisch, A.C., Schorr, L.B., Weiss, C.H., Eds.; The Aspen Institute for Humanistic Studies: New York, NY, USA, 1995; ISBN 0-89843-167-0.

17. Perez, I.G.; Cantergiani, C.; Boelman, V.; Davies, H.; Murphy-Evans, N. CLEVER Monitoring and Evaluation Framework. Available online: https:/ / clevercities.eu/resources/deliverables/ (accessed on 14 January 2021).

18. Mahmoud, I.; Morello, E. Co-creation Pathway for Urban Nature-Based Solutions: Testing a Shared-Governance Approach in Three Cities and Nine Action Labs. In Smart and Sustainable Planning for Cities and Regions: Results of SSPCR 2019—Open Access Contributions; Bisello, A., Vettorato, D., Ludlow, D., Baranzelli, C., Eds.; Springer International Publishing: Cham, Switzerland, 2021; pp. 259-276. ISBN 978-3-03-057764-3.

19. Hooghe, L.; Marks, G. Types of Multi-Level Governance. J. Eur. Integr. 2002, 5. [CrossRef]

20. Betsill, M.M.; Bulkeley, H. Cities and the Multi-level Governance of Global Climate Change. Glob. Gov. 2006, 12, 141-159. [CrossRef]

21. Frantzeskaki, N.; Rok, A. Co-producing urban sustainability transitions knowledge with community, policy and science. Environ. Innov. Soc. Transit. 2018, 29, 47-51. [CrossRef]

22. Dente, B. Understanding Policy Decisions; Springer: Cham, Switzerland, 2014; ISBN 978-3-319-02520-9.

23. Bryson, J.M. What to do when stakeholders matter: Stakeholder identification and analysis techniques. Public Manag. Rev. 2014, 6, 21-53. [CrossRef]

24. Konjaria-Christian, S.; Pastoors, J.; Arlati, A.; Rödl, A.; Berghausen, M.; Quanz, J.; Robert, J.; Carlini, G. CAL Specific coImplementation Plan. 2020. Available online: https:/ / clevercities.eu/resources/deliverables/ (accessed on 3 September 2020).

25. Statistisches Amt für Hamburg und Schleswig-Holstein. Bevölkerung in Hamburg am 31.12.2019: Auszählung aus dem Melderegister. Available online: https:/ / www.statistik-nord.de/fileadmin/Dokumente/Statistische_Berichte/bevoelkerung/ A_I_S_1_j_H/A_I_S1_j19.pdf (accessed on 15 October 2020).

26. Statistisches Amt für Hamburg und Schleswig-Holstein. Hamburger Stadtteil-Profile Berichtsjahr 2018. Available online: https:/ / www.statistik-nord.de/fileadmin/Dokumente/NORD.regional/NR21_Statistik-Profile_HH-2018.pdf (accessed on 15 October 2020).

27. Hamburg-stadtteile.de. Hamburg Stadtteile. Available online: http://www.hamburgs-stadtteile.de/hamburg/allnsbin/ (accessed on 4 January 2021).

28. Bezirk Harburg. Neugraben-Fischbek: Aktives Fördergebiet; Bezirk Harburg: Hamburg, Germany, 2017. Available online: https: //www.hamburg.de/harburg/rise-neugraben-fischbek/ (accessed on 3 September 2020).

29. Frei und Hansestadt Hamburg (FHH). Sozialmonitoring Integrierte Stadtteilentwicklung: Ergebnisbericht 2019. Available online: https:/ / www.hamburg.de/contentblob/13278936/8e978b2127057b0e459f30d81ef9f00c/data/d-sozialmonitoring-bericht2019.pdf (accessed on 3 September 2020). 
30. Morello, E.; Mahmoud, I.; Gulyurtlu, S.; Boelman, V.; Davis, H. CLEVER Cities Guidance on Co-Creating Nature-Based Solutions: PART I-Defining the Co-Creation Framework and Stakeholder Engagement. 2018. Available online: https://clevercities.eu/ resources/deliverables/ (accessed on 3 September 2020).

31. Bezirk Harburg. Das Projekt CLEVER Cities Nahm am Stadtteilfest 'Neugraben Erleben' 2019 Teil; Bezirk Harburg: Hamburg, Germany, 2019. Available online: https:/ / www.hamburg.de/harburg/horizon-2020-clever-cities/13703868/clever-cities-beineugraben-erleben/ (accessed on 3 September 2020).

32. Morello, E.; Mahmoud, I. CLEVER Cities-Co-Design Planning: Steps 07/08-Co-Creation Pathway. Available online: https: //clevercitiesguidance.files.wordpress.com/2019/10/steps-7-and-8-instructions.pdf (accessed on 18 February 2021).

33. Arnstein, S.R. A Ladder Of Citizen Participation. J. Am. Inst. Plan. 1969, 35, 216-224. [CrossRef]

34. Optigrün Dachbegrünung. Smart Flow Control SFC. Available online: https://www.optigruen.de/produkte/ablaufdrosseln/ smart-flow-control-sfc/ (accessed on 30 September 2020).

35. Connell, J.; Kubisch, A.C. Applying a Theory of Change Approach to the Evaluation of Comprehensive Community Initiatives: Progress, Prospects, and Problems. Available online: http://dmeforpeace.org/sites/default/files/080713\%20Applying+Theory+ of+Change+Approach.pdf (accessed on 30 September 2020).

36. Mauser, W.; Klepper, G.; Rice, M.; Schmalzbauer, B.S.; Hackmann, H.; Leemans, R.; Moore, H. Transdisciplinary global change research: The co-creation of knowledge for sustainability. Curr. Opin. Environ. Sustain. 2013, 5, 420-431. [CrossRef]

37. Vignola, R.; Locatelli, B.; Martinez, C.; Imbach, P. Ecosystem-based adaptation to climate change: What role for policy-makers, society and scientists? Mitig. Adapt. Strateg. Glob. Chang. 2009, 14, 691-696. [CrossRef]

38. Frantzeskaki, N.; Borgström, S.; Gorissen, L.; Egermann, M.; Ehnert, F. Nature-Based Solutions Accelerating Urban Sustainability Transitions in Cities: Lessons from Dresden, Genk and Stockholm Cities. In Nature-based Solutions to Climate Change Adaptation in Urban Areas: Linkages between Science, Policy and Practice; Kabisch, N., Korn, H., Stadler, J., Bonn, A., Eds.; Springer Imprint: Cham, Switzerland, 2017; pp. 65-88. ISBN 978-3-319-53750-4.

39. Dushkova, D.; Haase, D. Not Simply Green: Nature-Based Solutions as a Concept and Practical Approach for Sustainability Studies and Planning Agendas in Cities. Land 2020, 9, 19. [CrossRef]

40. Busetti, S.; Vecchi, G. Process tracing change management: The reform of the Italian judiciary. Int. J. Public Sect. Manag. 2018, 31, 566-582. [CrossRef]

41. Cantergiani, C.; Perez, I.G.; Menny, M.; Murphy-Evans, N.; Casagrande, S. UIP Launch: Urban Innovation Partnership (UIP) Launching. Available online: https:/ / clevercities.eu/resources/deliverables/ (accessed on 11 January 2021).

42. Mahmoud, I.; Morello, E. Are Nature-based solutions the answer to urban sustainability dilemma? The case of CLEVER Cities CALs within the Milanese urban context. In Proceedings of the Atti della XXII Conferenza Nazionale SIU., L'Urbanistica italiana di fronte all'Agenda 2030. L'Urbanistica italiana di fronte all'Agenda 2030. Portare territori e comunità sulla strada della sostenibilità e della resilienza, Matera-Bari, 5-7 June; Planum Publisher: Roma Milano, Italy, 2019; ISBN 9788899237219.

43. IUCN. Nature-Based Solutions to Address Global Societal Challenges; Cohen-Shacham, E., Walters, G., Janzen, C., Maginnis, S., Eds.; IUCN: Gland, Switzerland, 2016; ISBN 978-2-8317-1812-5.

44. Bulkeley, H.; Kern, K. Local Government and the Governing of Climate Change in Germany and the UK. Urban Stud. 2006, 43, 2237-2259. [CrossRef]

45. Kemp, R.; Loorbach, D.; Rotmans, J. Transition management as a model for managing processes of co-evolution towards sustainable development. Int. J. Sustain. Dev. World Ecol. 2009, 14, 78-91. [CrossRef] 